\title{
Effect of Freezing on Photosystem II and Assessment of Freezing Tolerance of Tea Cultivar
}

\author{
Yun-Long Shi ${ }^{D}$, Zhuo-Yu Cai, Da Li, Jian-Liang Lu, Jian-Hui Ye, Yue-Rong Liang *(D) and \\ Xin-Qiang Zheng *
}

Tea Research Institute, Zhejiang University, Hangzhou 310058, China; lonfucius@yahoo.com (Y.-L.S.); 21716160@zju.edu.cn (Z.-Y.C.); 21616098@zju.edu.cn (D.L.); jllu@zju.edu.cn (J.-L.L.); jx0515@163.com (J.-H.Y.)

* Correspondence: yrliang@zju.edu.cn (Y.-R.L.); xqzheng@zju.edu.cn (X.-Q.Z.); Tel.: +86-571-8898-2704 (Y.-R.L. \& X.-Q.Z.)

Received: 19 September 2019; Accepted: 19 October 2019; Published: 22 October 2019

\begin{abstract}
Freezing tolerant tea cultivars are urgently needed. The tea cultivars with highly freezing tolerance showed resistance to freezing stress induced photoinhibition. Freezing sensitivity index (H) of 47 tea clonal cultivars was investigated after severe freezing winter in 2016. To develop instrumental methods for freezing tolerance selection, the maximum photochemical efficiency of photosystem II (PSII) $(\mathrm{Fv} / \mathrm{Fm})$ and leaf color indicator $a$ on the Hunter color scale were determined on control group (non-frozen) and frozen group (being frozen at $-15^{\circ} \mathrm{C}$ for $2 \mathrm{~h}$ and then stood at $20^{\circ} \mathrm{C}$ for $5 \mathrm{~h}$ ) of the cultivars. When the two indicators were expressed as the ratios $\left(\mathrm{R}_{\mathrm{Fv} / \mathrm{Fm}}\right.$ and $\left.\mathrm{R}_{a}\right)$ of frozen group to control group, linear regression of the freezing sensitivity index $(\mathrm{H})$ upon the $\mathrm{R}_{\mathrm{Fv} / \mathrm{Fm}}$ and $\mathrm{R}_{a}$ produced significant relationship respectively, i.e., $\mathrm{H}=60.31-50.09 \mathrm{R}_{\mathrm{Fv} / \mathrm{Fm}}(p<0.01)$ and $\mathrm{H}=$ $30.03-10.82 \mathrm{R}_{a}(p<0.01)$. Expression of gene $p s b A$ encoding D1 protein and gene $p s b D$ encoding D2 protein in PSII showed that the frezzing tolerant tea cultivars maintained a high expression level of $p s b A$ after freezing stress, which is considered to be beneficial to de novo synthesis of D1 protein and sustaining PSII activity. These findings can provide instrumental tools for assessing freezing tolerance of tea cultivars in tea breeding program.
\end{abstract}

Keywords: Camellia sinensis; freezing tolerance; freezing sensitivity; overwintering; photosynthesis system; tea breeding

\section{Introduction}

Low temperature affects the growth, development, and productivity of tea plants, and severe freezing winter conditions at high latitudes limit the distribution of tea plants and the expansion of tea production areas. However, there are obvious differences in freezing tolerance between tea cultivars [1]. For example, tea cultivar 'Yinghong 1', bred from descendants of Camellia assamica could not survive in the lower reaches of Yangtze River around $30^{\circ} \mathrm{N}$ latitude where the lowest winter temperature is about $-6{ }^{\circ} \mathrm{C}$, whereas cultivar 'Lucha 1' bred from descendants of Camellia sinensis grows well in Qingdao City, China where the latitude is $36^{\circ} \mathrm{N}$ and the lowest winter temperature is below $-10^{\circ} \mathrm{C}$. Breeding and cultivating freezing tolerant tea cultivars is an effective way to conquer freezing stress in winter at high latitude tea areas.

Assessing the freezing tolerance of tea cultivar or tea line from the tested hybrid population or tea lines is a key technique for breeding freezing tolerance tea cultivar. To accelerate the freezing tolerance breeding, various indicators were introduced to evaluate the freezing tolerance potential of the tested tea cultivar. These indicators included the layers of palisade cell and the ratio of the palisade to spongy parenchyma in leaf transverse section [2], leaf electrolyte leakage after freezing treatment [3]. Transcriptome sequencing was also used to explore genes or DNA markers linked to cold tolerance of 
tea cultivar [4-8]. However, there is a long way to go for applying these indicators in tea breeding practices. Actually, field survey is still an indispensable method to evaluate the freezing tolerance of the tested tea lines, in which freezing-induced injuries of various tea accessions grown in the same field were assessed after severe freezing weather in winter. However, this operation is highly weather dependent and time consuming. The freezing tolerance assessment could not be carried if the winter was warm. It is necessary to develop feasible instrumental methods for assessing the freezing tolerance of tested tea cultivars to guide freezing resistance tea breeding.

Various ecotypes of crops showed distinct differences in their potential to acclimate to cold and hot stress [9]. Chloroplast, a photosynthesis site in a plant, is one of the first organelles affected by cold stress and it extremely sensitive to cold stress $[10,11]$. Chloroplast proteolytic machinery is involved in repairing damage incurred to the photosynthetic machinery upon exposure to cold stress [12]. The cold-tolerant ecotype of Valonia utricularis is able to cope with the applied low temperature stress by down-regulating the PSII RCs, whereas the cold-sensitive ecotype has a generally lower capacity for dynamic photoinhibition and sustains photodamage [13]. In rice, cold tolerance is connected to photosynthesis regulation [14]. The chilling-induced differences in chloroplast structure between cold sensitive and cold tolerant plants are the consequence of different thylakoid supercomplex rearrangements [15]. The PSII protein complex contains more than 20 subunits and includes both extrinsic and intrinsic membrane proteins [16]. Some intrinsic proteins including D1 protein encoded by gene $p s b A$ and $D 2$ protein encoded by gene $p s b D$ are required for phototroph growth and oxygen evolution. The deletion of these proteins causes disruption of the PSII assembly and function. The subunit structure of the intrinsic proteins has been highly conserved in higher plants and is necessary to allow oxygen evolution, while the extrinsic proteins have undergone a large evolutionary change [17]. PSII proteins can undergo posttranslational modifications associated with stress protection and repair and the PSII intrinsic proteins in cold tolerant plants have strong repair ability to prevent the photosynthetic system from the chilling-enhanced photooxidation and maintain a high photosynthetic capacity $[16,18]$. There is connection between cold tolerance and photosynthesis regulation in plant.

The freezing tolerance of crops was indirectly assessed by detecting their photosynthetic activity under freezing stress. Chlorophyll fluorescence (ChlF) and potential quantum yield of PSII (Fv/Fm), which characterize the activity of PSII RCs, were used as selection tools for improving the cold tolerance of crops such as maize, tomato and rice, which was largely due to the ability of the tolerant plants to keep higher efficiency of excitation energy capture by the PSII RCs [19-23]. The information on the relationship of photosynthetic regulation to freezing tolerance of tea cultivars has not been available.

Tea leaf is rich in tea polyphenols (TP) which are suspended in the leaf cell vacuoles. When the leaves are injured by mechanical action or environmental stress such as freezing or chloroform vapor, the TP in the leaves will be oxidized, resulting in browning of the leaves [24]. It is hypothesized that the changes of the leaf color depend on the severity of leaf injury and those from freezing sensitive cultivars will become more red brown owing to their serious damage induced by the freezing. Therefore, the present study is aimed to investigate the effects of freezing on the PSII activity and leaf color of various tea cultivars, so as to search a tool for screening freezing tolerant tea lines in tea breeding program.

\section{Results}

\subsection{Freezing Tolerance of Various Tea Cultivars}

The field survey results showed that among the forty seven tested cultivars, four was rated as freezing sensitive, with an $\mathrm{H}$ index $\geq 50.00$. Thirty-five was rated as moderate freezing sensitive, with $\mathrm{H}$ indexes ranging from 20.00 to $<50.00$. One was rated as freezing tolerant, with an $\mathrm{H}$ index 18.33 , and seven was rated as highly freezing-tolerant, with $H$ indexes $<10.0$ (Table 1). These suggest that there were obvious differences in freezing tolerance between various tea cultivars and cultivating 
tea cultivars with freezing tolerance will be an affective measure to conquer freezing winter weather in high latitude tea areas.

Table 1. Percentage of freezing-induced injured leaves of various cultivars ${ }^{1}$.

\begin{tabular}{|c|c|c|c|c|c|c|}
\hline Cultivars & Block 1 (\%) & Block $2(\%)$ & Block $3(\%)$ & Mean \pm SD (\%) & $\mathbf{H}$ & Freezing Tolerance \\
\hline $4-56$ & 16.06 & 18.32 & 17.40 & $17.263 \pm 1.138$ & 50.00 & Sensitive \\
\hline $5-62$ & 21.83 & 22.81 & 23.46 & $22.701 \pm 0.817$ & 50.00 & Sensitive \\
\hline FZ-0 & 16.08 & 16.75 & 17.40 & $16.741 \pm 0.660$ & 50.00 & Sensitive \\
\hline HJY & 20.51 & 23.08 & 23.06 & $22.217 \pm 1.478$ & 50.00 & Sensitive \\
\hline $1-17$ & 15.89 & 16.23 & 16.50 & $16.204 \pm 0.304$ & 48.33 & Moderate sensitive \\
\hline $4-57$ & 14.91 & 16.95 & 16.97 & $16.278 \pm 1.184$ & 48.33 & Moderate sensitive \\
\hline Zijuan & 15.41 & 13.79 & 16.71 & $15.303 \pm 1.465$ & 43.33 & Moderate sensitive \\
\hline $4-63$ & 14.23 & 14.08 & 14.22 & $14.178 \pm 0.083$ & 33.33 & Moderate sensitive \\
\hline $1-16$ & 13.78 & 13.36 & 12.95 & $13.364 \pm 0.417$ & 28.33 & Moderate sensitive \\
\hline $1-6$ & 14.55 & 13.17 & 12.11 & $13.279 \pm 1.226$ & 28.33 & Moderate sensitive \\
\hline JK-2 & 13.93 & 13.66 & 13.95 & $13.847 \pm 0.164$ & 28.33 & Moderate sensitive \\
\hline $4-14$ & 13.29 & 14.74 & 13.37 & $13.801 \pm 0.815$ & 26.67 & Moderate sensitive \\
\hline $2-49$ & 8.81 & 9.46 & 9.14 & $9.139 \pm 0.326$ & 25.00 & Moderate sensitive \\
\hline $2-7$ & 6.99 & 6.74 & 6.72 & $6.815 \pm 0.150$ & 25.00 & Moderate sensitive \\
\hline $3-1$ & 13.25 & 13.58 & 13.00 & $13.273 \pm 0.291$ & 25.00 & Moderate sensitive \\
\hline $3-10$ & 11.86 & 12.49 & 13.01 & $12.456 \pm 0.576$ & 25.00 & Moderate sensitive \\
\hline $4-152$ & 8.75 & 8.83 & 8.85 & $8.814 \pm 0.054$ & 25.00 & Moderate sensitive \\
\hline $4-154$ & 9.49 & 8.72 & 8.41 & $8.876 \pm 0.557$ & 25.00 & Moderate sensitive \\
\hline $4-17$ & 8.12 & 7.73 & 7.36 & $7.738 \pm 0.381$ & 25.00 & Moderate sensitive \\
\hline $4-38$ & 9.23 & 8.31 & 8.32 & $8.620 \pm 0.532$ & 25.00 & Moderate sensitive \\
\hline $4-44-4$ & 12.4 & 12.03 & 12.16 & $12.195 \pm 0.187$ & 25.00 & Moderate sensitive \\
\hline $4-45$ & 9.58 & 9.47 & 8.73 & $9.257 \pm 0.462$ & 25.00 & Moderate sensitive \\
\hline $4-6$ & 7.55 & 8.51 & 8.35 & $8.139 \pm 0.513$ & 25.00 & Moderate sensitive \\
\hline $4-76$ & 12.89 & 12.43 & 13.06 & $12.790 \pm 0.325$ & 25.00 & Moderate sensitive \\
\hline $5-47$ & 9.89 & 9.41 & 9.06 & $9.454 \pm 0.419$ & 25.00 & Moderate sensitive \\
\hline $5-72$ & 10.82 & 10.40 & 10.37 & $10.532 \pm 0.252$ & 25.00 & Moderate sensitive \\
\hline $5-81$ & 10.77 & 10.40 & 10.30 & $10.489 \pm 0.245$ & 25.00 & Moderate sensitive \\
\hline FZ-1 & 11.59 & 13.10 & 13.02 & $12.568 \pm 0.846$ & 25.00 & Moderate sensitive \\
\hline FZ-2 & 8.78 & 9.32 & 9.13 & $9.076 \pm 0.272$ & 25.00 & Moderate sensitive \\
\hline PBZY & 10.61 & 10.51 & 10.03 & $10.384 \pm 0.309$ & 25.00 & Moderate sensitive \\
\hline ZNB & 10.20 & 10.72 & 10.24 & $10.385 \pm 0.288$ & 25.00 & Moderate sensitive \\
\hline Fuding & 11.93 & 11.94 & 11.75 & $11.875 \pm 0.106$ & 25.00 & Moderate sensitive \\
\hline Fuwuming & 7.93 & 8.54 & 8.62 & $8.367 \pm 0.377$ & 25.00 & Moderate sensitive \\
\hline Jinxuan & 10.35 & 10.45 & 10.07 & $10.29 \pm 0.195$ & 25.00 & Moderate sensitive \\
\hline Xiangshan 3 & 7.80 & 8.05 & 7.91 & $7.921 \pm 0.126$ & 25.00 & Moderate sensitive \\
\hline Xiangshan 5 & 9.59 & 10.35 & 10.44 & $10.127 \pm 0.463$ & 25.00 & Moderate sensitive \\
\hline Zhenghe & 7.48 & 8.37 & 7.66 & $7.838 \pm 0.467$ & 25.00 & Moderate sensitive \\
\hline $1-18$ & 7.96 & 7.51 & 6.30 & $7.255 \pm 0.859$ & 23.33 & Moderate sensitive \\
\hline Z-7 & 4.90 & 5.97 & 5.48 & $5.450 \pm 0.532$ & 20.00 & Moderate sensitive \\
\hline $5-28$ & 5.19 & 5.42 & 5.09 & $5.229 \pm 0.169$ & 18.33 & Tolerant \\
\hline $1-35$ & 4.53 & 4.00 & 2.97 & $3.832 \pm 0.792$ & 1.67 & Highly tolerant \\
\hline $1-10$ & 0.22 & 0.21 & 0.20 & $0.209 \pm 0.006$ & 0 & Highly tolerant \\
\hline $4-52$ & 0.24 & 0.59 & 0.58 & $0.469 \pm 0.198$ & 0 & Highly tolerant \\
\hline $4-52-2$ & 0.45 & 0.48 & 0.44 & $0.457 \pm 0.022$ & 0 & Highly tolerant \\
\hline 4-77 & 0.67 & 0.83 & 0.56 & $0.687 \pm 0.136$ & 0 & Highly tolerant \\
\hline FYWM-3 & 1.77 & 2.16 & 1.37 & $1.768 \pm 0.395$ & 0 & Highly tolerant \\
\hline FYWM-7 & 2.42 & 2.66 & 2.48 & $2.519 \pm 0.126$ & 0 & Highly tolerant \\
\hline
\end{tabular}

${ }^{1}$ The freezing-induced injured leaves and total leaves of 5 plants each block was counted and the percentage of the freezing-induced injured leaves was expressed as (total injured leaves/total leaves) $\times 100 \%$. The $\mathrm{H}$ index was calculated by equation $\left(\mathrm{H}(\%)=\left[\Sigma\left(\mathrm{n}_{i} \times \mathrm{x}_{i}\right) /(\mathrm{N} \times 4)\right] \times 100\right)$ described in Section 4.2.

\subsection{Effects of Freezing on Fo/Fm of Leaves of Various Tea Cultivars}

$\mathrm{Fv} / \mathrm{Fm}$ is an indicator of the maximum photochemical efficiency of PSII and it can be used to assess the PSII activity [25]. The Fv/Fm was determined from the ratio of variable (Fv) to maximum $(\mathrm{Fm})$ fluorescence $\left(\mathrm{Fv} / \mathrm{Fm}=\left(\mathrm{Fm}-\mathrm{F}_{0}\right) / \mathrm{Fm}\right)[26]$. Table 2 shows that the mean value of $\mathrm{Fv} / \mathrm{Fm}$ was significantly decreased from 0.745 to $0.526(p<0.001)$. The mean value of $\mathrm{Fv} / \mathrm{Fm}$ ratio of frozen group to control group was 0.706 , suggesting that $29.4 \%$ of the maximum photochemical efficiency of PSII was 
lost after freezing treatment, in which there were obvious differences in the freezing-induced decrease in Fv/Fm value between tea cultivars, ranging from a decrease by $66.3 \%$ (freezing sensitive cultivar '5-62') to a decrease by $4.2 \%$ (highly freezing tolerant cultivar '4-52') (Tables 1 and 2). These suggest that the responses of various tea cultivars to the freezing-induced decrease in Fv/Fm were differentiated, in which it decreased more in freezing sensitive cultivars than highly freezing-tolerant cultivars.

Table 2. Effects of freezing on Fv/Fm in leaves of various tea cultivars.

\begin{tabular}{|c|c|c|c|}
\hline Cultivars & Frozen Group & Control Group & $\mathrm{R}_{\mathrm{Fv} / \mathrm{Fm}}{ }^{1}$ \\
\hline $1-10$ & $0.642 \pm 0.055$ & $0.732 \pm 0.023$ & 0.877 \\
\hline $1-16$ & $0.400 \pm 0.055$ & $0.749 \pm 0.025$ & 0.534 \\
\hline $1-17$ & $0.493 \pm 0.126$ & $0.709 \pm 0.032$ & 0.695 \\
\hline $1-18$ & $0.524 \pm 0.061$ & $0.747 \pm 0.031$ & 0.701 \\
\hline $1-35$ & $0.573 \pm 0.059$ & $0.724 \pm 0.013$ & 0.791 \\
\hline $1-6$ & $0.304 \pm 0.061$ & $0.767 \pm 0.011$ & 0.396 \\
\hline $2-49$ & $0.625 \pm 0.039$ & $0.742 \pm 0.021$ & 0.842 \\
\hline $2-7$ & $0.649 \pm 0.034$ & $0.708 \pm 0.027$ & 0.917 \\
\hline $3-1$ & $0.478 \pm 0.046$ & $0.763 \pm 0.012$ & 0.626 \\
\hline $3-10$ & $0.535 \pm 0.044$ & $0.747 \pm 0.026$ & 0.716 \\
\hline $4-14$ & $0.447 \pm 0.093$ & $0.758 \pm 0.010$ & 0.590 \\
\hline $4-152$ & $0.651 \pm 0.034$ & $0.754 \pm 0.015$ & 0.863 \\
\hline $4-154$ & $0.624 \pm 0.053$ & $0.778 \pm 0.013$ & 0.802 \\
\hline $4-17$ & $0.627 \pm 0.053$ & $0.746 \pm 0.033$ & 0.840 \\
\hline $4-38$ & $0.542 \pm 0.059$ & $0.724 \pm 0.038$ & 0.749 \\
\hline $4-44-4$ & $0.390 \pm 0.101$ & $0.750 \pm 0.022$ & 0.520 \\
\hline $4-45$ & $0.647 \pm 0.039$ & $0.781 \pm 0.031$ & 0.828 \\
\hline $4-52$ & $0.700 \pm 0.046$ & $0.731 \pm 0.036$ & 0.958 \\
\hline $4-52-2$ & $0.701 \pm 0.017$ & $0.753 \pm 0.023$ & 0.931 \\
\hline $4-56$ & $0.329 \pm 0.109$ & $0.769 \pm 0.037$ & 0.428 \\
\hline $4-57$ & $0.519 \pm 0.057$ & $0.794 \pm 0.022$ & 0.654 \\
\hline $4-6$ & $0.520 \pm 0.042$ & $0.705 \pm 0.074$ & 0.738 \\
\hline $4-63$ & $0.285 \pm 0.075$ & $0.744 \pm 0.022$ & 0.383 \\
\hline $4-76$ & $0.310 \pm 0.102$ & $0.768 \pm 0.016$ & 0.404 \\
\hline $4-77$ & $0.576 \pm 0.130$ & $0.766 \pm 0.030$ & 0.752 \\
\hline $5-28$ & $0.685 \pm 0.044$ & $0.766 \pm 0.020$ & 0.894 \\
\hline $5-47$ & $0.570 \pm 0.068$ & $0.748 \pm 0.021$ & 0.762 \\
\hline $5-62$ & $0.246 \pm 0.042$ & $0.731 \pm 0.008$ & 0.337 \\
\hline $5-72$ & $0.544 \pm 0.057$ & $0.729 \pm 0.040$ & 0.746 \\
\hline 5-81 & $0.479 \pm 0.044$ & $0.774 \pm 0.025$ & 0.619 \\
\hline FYWM 3 & $0.694 \pm 0.032$ & $0.739 \pm 0.021$ & 0.939 \\
\hline FYWM 7 & $0.690 \pm 0.026$ & $0.746 \pm 0.031$ & 0.925 \\
\hline FZ-0 & $0.340 \pm 0.107$ & $0.690 \pm 0.054$ & 0.493 \\
\hline FZ-1 & $0.455 \pm 0.068$ & $0.745 \pm 0.043$ & 0.611 \\
\hline FZ-2 & $0.604 \pm 0.012$ & $0.731 \pm 0.029$ & 0.826 \\
\hline $\mathrm{JK} 2$ & $0.409 \pm 0.066$ & $0.739 \pm 0.031$ & 0.553 \\
\hline PBZY & $0.540 \pm 0.087$ & $0.733 \pm 0.034$ & 0.737 \\
\hline $\mathrm{Z}-7$ & $0.642 \pm 0.098$ & $0.764 \pm 0.027$ & 0.840 \\
\hline ZNB & $0.579 \pm 0.069$ & $0.773 \pm 0.021$ & 0.749 \\
\hline Fuding & $0.550 \pm 0.084$ & $0.761 \pm 0.029$ & 0.723 \\
\hline Fuwuming & $0.633 \pm 0.056$ & $0.759 \pm 0.026$ & 0.834 \\
\hline HJY & $0.596 \pm 0.051$ & $0.730 \pm 0.021$ & 0.816 \\
\hline Jinxuan & $0.467 \pm 0.098$ & $0.720 \pm 0.012$ & 0.649 \\
\hline Xiangshan 3 & $0.597 \pm 0.047$ & $0.760 \pm 0.013$ & 0.786 \\
\hline Xiangshan 5 & $0.475 \pm 0.022$ & $0.733 \pm 0.013$ & 0.648 \\
\hline Zhenghe & $0.501 \pm 0.076$ & $0.732 \pm 0.015$ & 0.684 \\
\hline Zijuan & $0.331 \pm 0.138$ & $0.725 \pm 0.044$ & 0.457 \\
\hline Mean & $0.526^{*}$ & 0.745 & 0.706 \\
\hline
\end{tabular}

\footnotetext{
${ }^{1} \mathrm{R}_{\mathrm{Fv} / \mathrm{Fm}}$ : The $\mathrm{Fv} / \mathrm{Fm}$ ratio of the frozen group to the control group, ${ }^{*}$ Being significantly different from that in control leaves at $p<0.001$.
} 
Statistics showed that the Pearson's linear correlation coefficient $(r)$ between freezing sensitivity index $(\mathrm{H})$ and $\mathrm{Fv} / \mathrm{Fm}$ ratio of frozen group to control group $\left(\mathrm{R}_{\mathrm{Fv} / \mathrm{Fm}}\right)$ was $-0.610(p<0.01)$, with a linear regressive relationship as $\mathrm{H}=60.31-50.09 \mathrm{R}_{\mathrm{Fv} / \mathrm{Fm}}(p<0.01, \mathrm{n}=47)$ (Table S1), suggesting that the freezing tolerance of a tea cultivar can be predicted by its $\mathrm{R}_{\mathrm{Fv} / \mathrm{Fm}}$ value.

\subsection{Effects of Freezing on Expression of Genes Involved in PSII Proteins D1 and D2}

The photosynthetic proteins play an important role in preventing PSII from photodamage under environmental stress conditions [27,28]. Among the various subunits in the PSII reaction center (RC), D1 protein encoded by chloroplast $p s b A$ is a major target that is easily injured by environmental stress [29]. The timely synthesis of new D1 protein is key to PSII functional recovery [30] and D2 protein encoded by $p s b D$ gene is closely related to the repair of $D 1$ protein [31]. Therefore, the transcription of the $p s b A$ and $p s b D$ genes plays an extremely important role in the process of D1 protein turnover and PSII function during environmental stress conditions [32]. The present study showed that the expression of $p s b A$ and $p s b D$ in the freezing sensitive cultivar '5-62' was significantly decreased by freezing treatment $(p<0.05)$. However, the expression patterns of these two genes in highly freezing-tolerant cultivars such as ' $4-52$ ' and '4-77' were differentiated by freezing treatment, in which $p s b A$ was significantly upregulated $(p<0.05)$ while $p s b D$ was downregulated. There were no significant differences in expression of $p s b A$ in moderate freezing-sensitive cultivars ' $5-72$ ' and 'Fuding' after freezing treatment (Figure 1). The freezing-induced upregulation of $p s b A$ gene in the highly freezing-tolerant tea cultivars might be beneficial to the balance of D1 protein and the PSII functional recovery during freezing stress. No obvious relationship was observed between the cold sensitivity index $\mathrm{H}$ and the expression level of $p s b D$ (Figure 2).

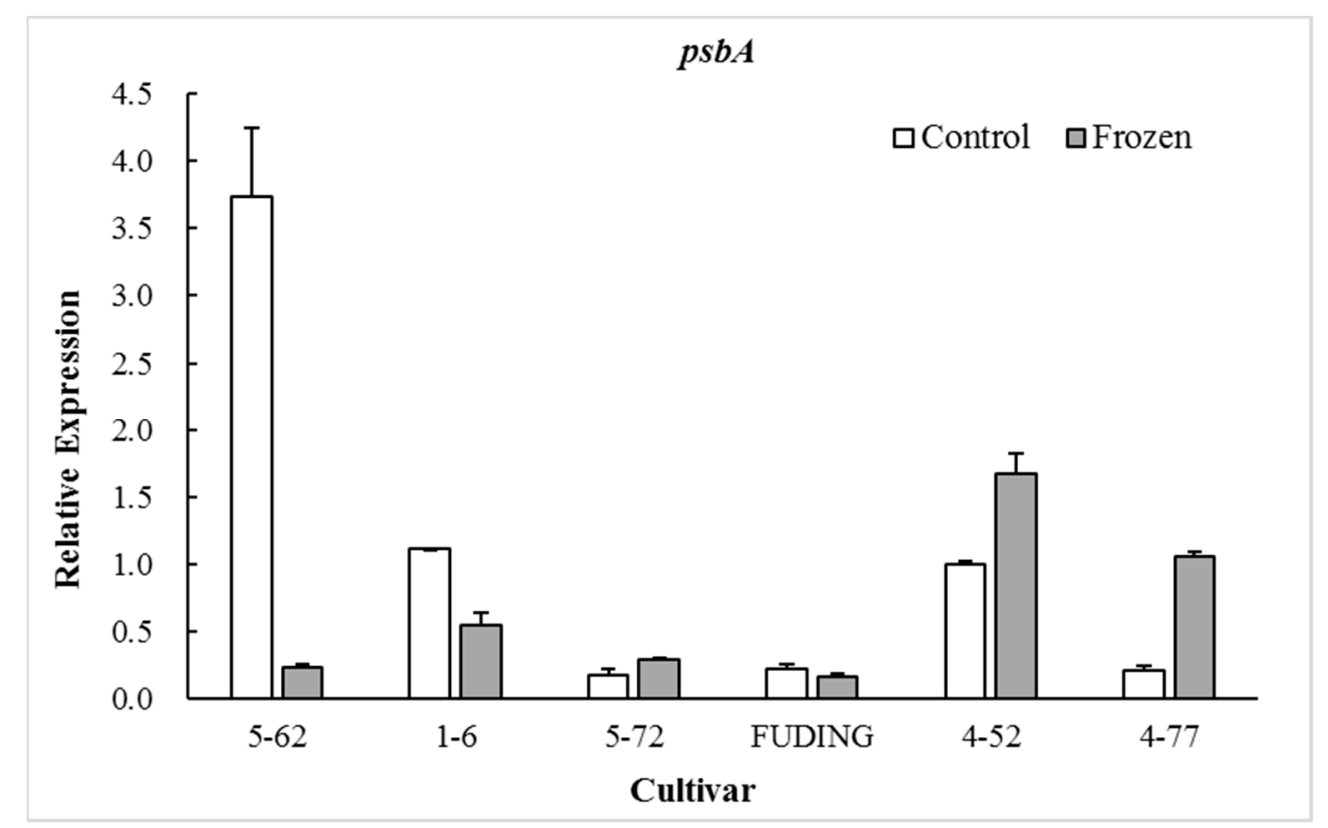

Figure 1. Effect of freezing on the expression of gene $p s b A$.

When calculating the relative expression values, the tested data were firstly normalized using $\beta$-actin as an internal reference, and then made relative to the control of ' $4-52$ ' in which the expression value of '4-52' control was fixed as 1.0.

When calculating the relative expression values, the tested data were firstly normalized using $\beta$-actin as an internal reference, and then made relative to the control of ' $4-52^{\prime}$ in which the expression value of '4-52' control was fixed as 1.0. 


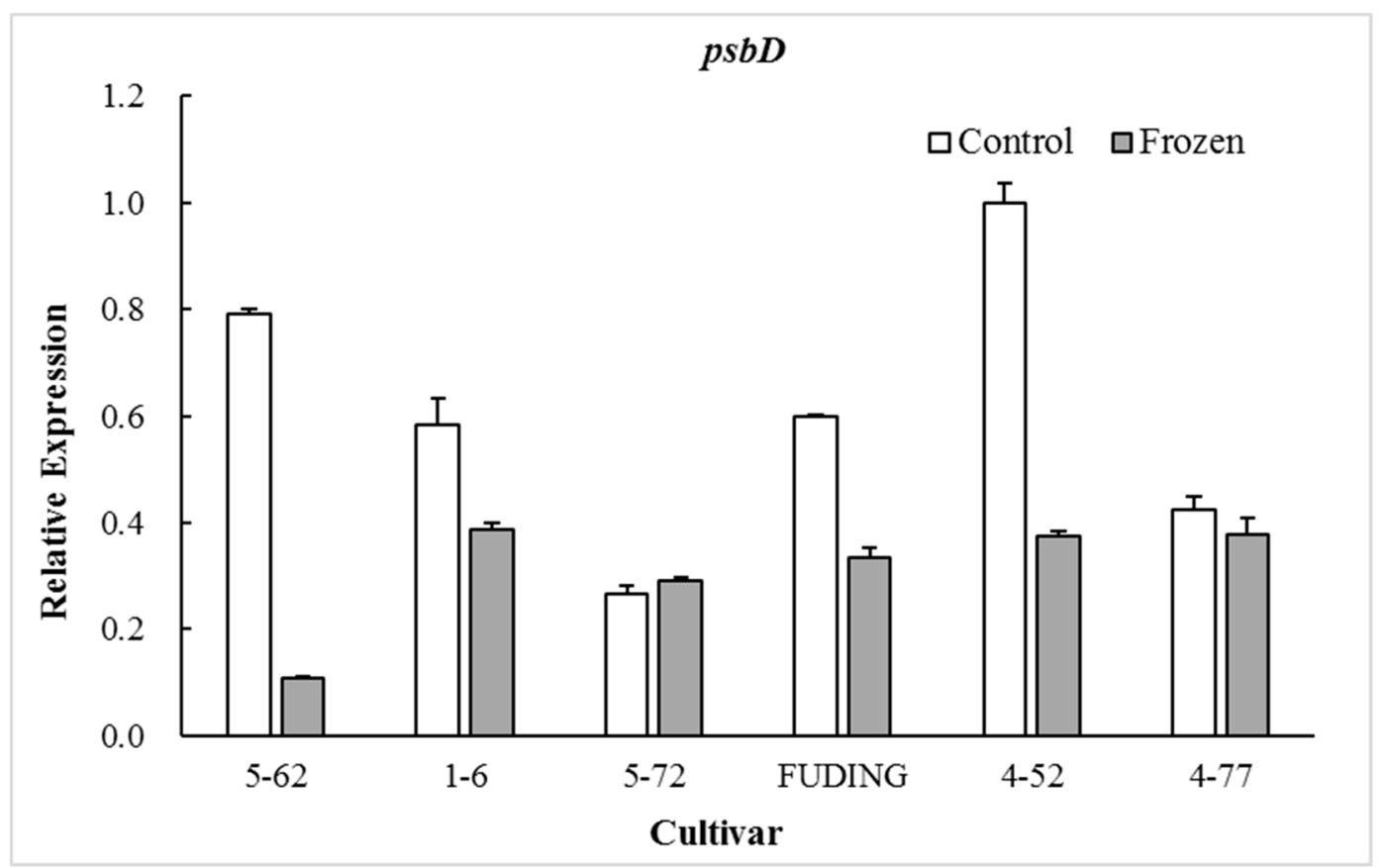

Figure 2. Effect of freezing on the expression of gene $p s b D$.

\subsection{Effects of Freezing on Leaf Color of Various Tea Cultivars}

When values on Hunter color scales were used as color indicators, it was showed that the light-dark scale $L$ value and green-red scale $a$ value were significantly increased, whereas the blue-yellow scale $b$ value significantly decreased after freezing treatment (Table 3 ). The $L$ is a white-black indicator, in which the sample would be a perfect reflecting diffuser when the $L$ is at maximum value 100 , and it would be black when the $L$ is at minimum value 0 . The $a$ value is a green-red indicator, in which a positive $a$ represents red color and a negative $a$ represents green color. The $b$ value is a blue-yellow indicator, in which a positive $b$ suggests the sample is in yellow color and a negative $b$ suggests the sample is in blue color [33]. The increase in the L value of the frozen group suggests that the color of the frozen leaves became lighter than the leaf color of control group after freezing treatment. The increase of value $a$ from -11.66 to -6.27 in the frozen group suggests that the frozen leaves were less green in color than the control leaves. These might partially be due to the freezing-induced degradation of leaf photosynthetic pigments such as chlorophylls, and partially be due to the oxidation of foliar TP. The decrease in the $b$ in the frozen leaves implies the frozen leaves became less yellow in color, which might be due to the loss of yellow pigments such as carotenoids.

Analysis of the Pearson's linear correlation coefficient ( $\mathrm{r}$ ) showed that there was a significantly negative correlation between the freezing sensitivity index $(\mathrm{H})$ and the ratio of frozen group $a$ to control group $a\left(\mathrm{R}_{a}\right)(\mathrm{r}=-0.480, p<0.01, \mathrm{n}=47)$, with a linear regressive relationship as $\mathrm{H}=30.03-10.82 \mathrm{R}_{a}$ $(p<0.01)$ (Table $\mathrm{S} 1)$, suggesting that the freezing tolerance of a tea cultivar can be predicted by its $\mathrm{R}_{a}$ value. The freezing sensitivity index $H$ was not significantly correlated to the indicators $R_{L}$ and $R_{b}$ (Table S1). 
Table 3. Effects of freezing on indicators of Hunter color scales.

\begin{tabular}{|c|c|c|c|c|c|c|}
\hline \multirow{2}{*}{$\begin{array}{c}\text { Color Indicator } \\
\text { Treatment }\end{array}$} & \multicolumn{2}{|c|}{$L$} & \multicolumn{2}{|c|}{$a$} & \multicolumn{2}{|c|}{$b$} \\
\hline & Control & Frozen & Control & Frozen & Control & Frozen \\
\hline $1-10$ & $20.69 \pm 2.20$ & $21.83 \pm 3.33$ & $-11.09 \pm 0.63$ & $-8.09 \pm 0.11$ & $32.33 \pm 1.69$ & $30.18 \pm 1.77$ \\
\hline $1-16$ & $21.27 \pm 1.17$ & $22.08 \pm 1.79$ & $-1.1 \pm 0.40$ & $-5.13 \pm 1.00$ & $33.44 \pm 0.83$ & $34.75 \pm 3.14$ \\
\hline $1-17$ & $24.23 \pm 2.09$ & $24.76 \pm 2.66$ & $-12.25 \pm 0.54$ & $-7.25 \pm 1.66$ & $40.74 \pm 3.47$ & $38.12 \pm 4.29$ \\
\hline $1-18$ & $21.41 \pm 1.46$ & $23.55 \pm 3.07$ & $-10.98 \pm 0.72$ & $-5.40 \pm 1.00$ & $36.27 \pm 2.40$ & $36.68 \pm 2.89$ \\
\hline $1-35$ & $24.05 \pm 2.01$ & $21.23 \pm 3.46$ & $-11.78 \pm 0.28$ & $-8.39 \pm 1.27$ & $38.53 \pm 4.38$ & $34.22 \pm 4.28$ \\
\hline $1-6$ & $25.96 \pm 3.67$ & $22.94 \pm 2.10$ & $-11.78 \pm 0.96$ & $-4.86 \pm 1.48$ & $43.07 \pm 5.43$ & $36.28 \pm 2.82$ \\
\hline $2-49$ & $19.14 \pm 1.14$ & $21.41 \pm 5.00$ & $-12.24 \pm 0.77$ & $-6.59 \pm 1.64$ & $31.28 \pm 1.59$ & $30.83 \pm 4.72$ \\
\hline $2-7$ & $22.37 \pm 2.47$ & $23.53 \pm 2.63$ & $-11.31 \pm 0.75$ & $-7.38 \pm 0.57$ & $37.20 \pm 3.66$ & $36.60 \pm 2.70$ \\
\hline $3-1$ & $21.52 \pm 2.14$ & $23.11 \pm 0.81$ & $-12.88 \pm 0.27$ & $-5.66 \pm 0.92$ & $35.93 \pm 3.15$ & $36.06 \pm 0.63$ \\
\hline $3-10$ & $21.27 \pm 1.64$ & $18.42 \pm 1.02$ & $-11.46 \pm 0.34$ & $-7.35 \pm 0.35$ & $35.23 \pm 2.52$ & $29.88 \pm 1.47$ \\
\hline 4-14 & $17.40 \pm 1.59$ & $22.44 \pm 2.36$ & $-11.14 \pm 0.35$ & $-4.97 \pm 0.40$ & $29.58 \pm 2.63$ & $35.12 \pm 2.54$ \\
\hline $4-152$ & $20.45 \pm 2.43$ & $23.12 \pm 1.60$ & $-12.50 \pm 0.53$ & $-7.09 \pm 1.24$ & $34.01 \pm 3.82$ & $35.32 \pm 6.64$ \\
\hline $4-154$ & $25.39 \pm 2.55$ & $27.62 \pm 2.98$ & $-11.41 \pm 0.62$ & $-6.04 \pm 1.02$ & $41.37 \pm 3.86$ & $39.51 \pm 3.48$ \\
\hline $4-17$ & $21.55 \pm 0.93$ & $22.38 \pm 0.68$ & $-11.09 \pm 0.95$ & $-7.70 \pm 1.34$ & $34.32 \pm 2.18$ & $33.69 \pm 2.40$ \\
\hline $4-38$ & $23.09 \pm 1.54$ & $23.29 \pm 1.12$ & $-11.42 \pm 0.32$ & $-6.73 \pm 0.23$ & $38.62 \pm 2.55$ & $36.08 \pm 2.94$ \\
\hline $4-44-4$ & $22.69 \pm 3.32$ & $23.43 \pm 1.20$ & $-12.43 \pm 0.51$ & $-5.82 \pm 1.22$ & $35.79 \pm 5.91$ & $35.11 \pm 2.46$ \\
\hline $4-45$ & $19.75 \pm 1.68$ & $23.18 \pm 1.94$ & $-11.93 \pm 0.67$ & $-5.69 \pm 1.08$ & $31.05 \pm 3.35$ & $34.17 \pm 3.66$ \\
\hline $4-52$ & $21.56 \pm 3.14$ & $24.77 \pm 2.97$ & $-12.96 \pm 0.40$ & $-10.72 \pm 0.39$ & $32.45 \pm 3.53$ & $29.27 \pm 1.45$ \\
\hline $4-52-2$ & $23.21 \pm 2.19$ & $23.93 \pm 3.42$ & $-12.71 \pm 0.45$ & $-8.43 \pm 1.07$ & $32.20 \pm 1.98$ & $34.44 \pm 5.17$ \\
\hline $4-56$ & $19.91 \pm 1.90$ & $23.59 \pm 3.53$ & $-12.02 \pm 0.61$ & $-4.38 \pm 1.23$ & $33.49 \pm 2.94$ & $34.69 \pm 4.89$ \\
\hline $4-57$ & $26.29 \pm 0.90$ & $25.41 \pm 3.21$ & $-12.25 \pm 1.47$ & $-6.33 \pm 1.07$ & $43.11 \pm 0.86$ & $37.86 \pm 4.93$ \\
\hline $4-6$ & $21.42 \pm 1.06$ & $20.76 \pm 1.71$ & $-12.08 \pm 0.50$ & $-4.87 \pm 1.17$ & $32.20 \pm 3.44$ & $30.72 \pm 3.68$ \\
\hline $4-63$ & $22.50 \pm 2.38$ & $21.74 \pm 2.11$ & $-12.60 \pm 0.49$ & $-3.85 \pm 0.28$ & $37.52 \pm 3.55$ & $33.06 \pm 5.56$ \\
\hline $4-76$ & $19.71 \pm 2.91$ & $24.55 \pm 2.60$ & $-12.30 \pm 0.89$ & $-4.72 \pm 0.65$ & $33.04 \pm 4.50$ & $35.75 \pm 4.41$ \\
\hline $4-77$ & $21.90 \pm 1.37$ & $24.22 \pm 2.84$ & $-13.01 \pm 1.08$ & $-12.16 \pm 1.25$ & $34.39 \pm 2.17$ & $37.74 \pm 4.89$ \\
\hline $5-28$ & $22.95 \pm 2.02$ & $22.00 \pm 1.22$ & $-11.90 \pm 0.34$ & $-7.71 \pm 1.19$ & $35.77 \pm 2.64$ & $33.96 \pm 3.19$ \\
\hline $5-47$ & $22.49 \pm 1.80$ & $22.38 \pm 2.42$ & $-12.79 \pm 0.38$ & $-5.92 \pm 0.99$ & $37.98 \pm 2.93$ & $35.68 \pm 3.23$ \\
\hline $5-62$ & $22.20 \pm 2.34$ & $20.67 \pm 3.29$ & $-11.43 \pm 0.79$ & $2.48 \pm 1.91$ & $34.03 \pm 1.94$ & $31.05 \pm 1.94$ \\
\hline $5-72$ & $21.52 \pm 1.98$ & $23.15 \pm 1.26$ & $-11.23 \pm 0.45$ & $-6.18 \pm 0.96$ & $34.13 \pm 3.02$ & $36.89 \pm 2.02$ \\
\hline 5-81 & $21.47 \pm 2.38$ & $20.20 \pm 2.21$ & $-12.84 \pm 0.75$ & $-9.89 \pm 1.01$ & $33.32 \pm 1.89$ & $30.58 \pm 2.42$ \\
\hline FYWM3 & $20.29 \pm 2.06$ & $22.94 \pm 2.73$ & $-11.65 \pm 0.87$ & $-9.31 \pm 0.44$ & $34.38 \pm 3.37$ & $36.93 \pm 2.65$ \\
\hline FYWM7 & $24.44 \pm 2.34$ & $20.89 \pm 1.34$ & $-10.56 \pm 0.85$ & $-8.88 \pm 0.94$ & $32.54 \pm 3.88$ & $32.75 \pm 0.72$ \\
\hline FZ-0 & $26.53 \pm 0.97$ & $27.34 \pm 2.91$ & $-10.84 \pm 0.29$ & $-3.87 \pm 1.97$ & $43.73 \pm 1.80$ & $41.35 \pm 1.53$ \\
\hline FZ-1 & $18.08 \pm 0.51$ & $20.76 \pm 1.57$ & $-11.15 \pm 0.48$ & $-4.8 \pm 0.81$ & $30.64 \pm 0.72$ & $33.29 \pm 2.72$ \\
\hline FZ-2 & $22.19 \pm 1.09$ & $23.61 \pm 1.14$ & $-12.48 \pm 0.62$ & $-8.35 \pm 0.87$ & $37.27 \pm 1.72$ & $37.60 \pm 1.70$ \\
\hline $\mathrm{JK}-2$ & $24.97 \pm 2.29$ & $28.29 \pm 3.87$ & $-12.81 \pm 0.61$ & $-4.79 \pm 0.88$ & $39.31 \pm 4.67$ & $35.04 \pm 2.83$ \\
\hline PBZY & $19.29 \pm 2.05$ & $23.30 \pm 2.33$ & $-11.48 \pm 0.34$ & $-6.21 \pm 0.63$ & $31.48 \pm 2.42$ & $28.66 \pm 8.03$ \\
\hline Z-7 & $21.95 \pm 2.22$ & $23.13 \pm 0.56$ & $-11.49 \pm 1.01$ & $-9.86 \pm 2.12$ & $36.18 \pm 4.06$ & $35.65 \pm 2.07$ \\
\hline ZNB & $20.56 \pm 0.80$ & $22.17 \pm 1.38$ & $-12.46 \pm 0.37$ & $-7.84 \pm 1.17$ & $33.49 \pm 1.89$ & $31.98 \pm 4.45$ \\
\hline Fuding & $20.77 \pm 1.92$ & $24.26 \pm 2.43$ & $-11.94 \pm 0.53$ & $-6.82 \pm 1.18$ & $34.95 \pm 2.76$ & $30.20 \pm 6.12$ \\
\hline Fuwuming & $26.96 \pm 1.96$ & $30.77 \pm 3.99$ & $-13.24 \pm 1.68$ & $-7.14 \pm 1.66$ & $40.41 \pm 3.33$ & $41.88 \pm 5.85$ \\
\hline HJY & $54.26 \pm 11.34$ & $43.60 \pm 5.68$ & $-1.79 \pm 5.67$ & $5.98 \pm 2.95$ & $59.5 \pm 11.79$ & $50.25 \pm 2.68$ \\
\hline Jinxuan & $21.22 \pm 3.27$ & $20.28 \pm 1.82$ & $-10.12 \pm 0.70$ & $-7.06 \pm 0.48$ & $35.82 \pm 5.58$ & $33.69 \pm 3.14$ \\
\hline Xiangshan 3 & $18.85 \pm 1.58$ & $24.94 \pm 4.64$ & $-11.56 \pm 0.66$ & $-7.42 \pm 0.55$ & $30.70 \pm 2.24$ & $34.99 \pm 5.59$ \\
\hline Xiangshan 5 & $18.55 \pm 1.01$ & $19.87 \pm 1.35$ & $-12.21 \pm 0.55$ & $-5.98 \pm 1.4$ & $31.52 \pm 1.69$ & $32.38 \pm 2.05$ \\
\hline Zhenghe & $22.83 \pm 2.11$ & $22.48 \pm 1.63$ & $-10.9 \pm 0.85$ & $-7.25 \pm 0.66$ & $29.40 \pm 2.60$ & $31.51 \pm 3.42$ \\
\hline Zijuan & $23.19 \pm 1.76$ & $25.74 \pm 1.59$ & $-12.21 \pm 0.42$ & $-2.44 \pm 0.81$ & $37.45 \pm 2.26$ & $35.41 \pm 2.64$ \\
\hline Mean & 22.64 & $23.62 *$ & -11.66 & $-6.27^{* *}$ & 35.77 & $34.85^{*}$ \\
\hline
\end{tabular}

* Being significantly different from that of the control group at $p<0.05,{ }^{* *}$ Being significantly different from that of the control group at $p<0.01$.

\section{Discussion}

Distribution of tea cultivars depends on their freezing tolerance. Cultivating tea cultivars with high freezing-tolerance is very important for the high latitude tea areas where the winter is severely cold. Tea plants were originated in tropical mountainous areas and they were usually sensitive to freezing environments, especially in the areas with severe winters. With the continuous expansion 
of tea planting areas to the high latitude areas and the artificial selection of cultivars, the freezing tolerance of tea plants or cultivars have been differentiated genetically [7]. Table 1 reveals that the tea cultivars with various freezing tolerances showed normal distribution rules, i.e., most of the cultivars showed moderate freezing-tolerant, while a few showed highly freezing sensitive or freezing-tolerant, being consistent with the previous reports [34,35]. It is feasible to screen some tea plant individuals or lines from the existing tea germplasm resources or hybrids. However, the manual selection based on field surveys depends on weather conditions and it will take several years. It is necessary to develop objective instrumental methods for screening lines or plant individuals with high freezing-tolerance from the existing breeding materials (hybrid descendants, radiation and chemical induced mutants and natural mutants).

Freezing stress severely affects the growth and development of plants. The present study showed that there were obvious differences in freezing tolerance between tea cultivars (Table 1), and these differences could be identified according to the freezing-induced changes in Fv/Fm of the tea leaves $\left(\mathrm{R}_{\mathrm{Fv} / \mathrm{Fm}}\right)$ (Tables 1 and 2). Based on these findings, the present paper reveals a linear regressive relationship between freezing sensitivity index $(\mathrm{H})$ and $\mathrm{Fv} / \mathrm{Fm}$ ratio of frozen group to control group $\left(\mathrm{H}_{\mathrm{Fv} / \mathrm{Fm}}\right): \mathrm{H}=60.31-50.09 \mathrm{R}_{\mathrm{Fv} / \mathrm{Fm}}(p<0.01)$ (Table $\left.\mathrm{S} 1\right)$. Chloroplast is extremely sensitive to low temperature stress and also one of the first organelles affected by suboptimal growing temperature [11]. Low temperature stress induced thylakoid super-complex rearrangements, resulting in differentiation of chloroplast structure between cold sensitive and cold tolerant plants [15]. Chilling induced changes in the grana thylakoid fluidity could distort the balance of photosystem rearrangements, resulting in sensitivity of cucumber to chilling [10]. Various ecotypes (Valonia utricularis) were differentiated in their potential to acclimate to suboptimal growth temperatures [9]. Cold stress led to reductions in photosynthetic rate in Elymus [36]. The primary freezing-triggered damage could be partially repaired, but further freezing-triggered dysfunction of the electron transfer between the PSII RCs and the primary quinone electron acceptor of PSII (QA) was connected with secondary damage leading to PSII deactivation. The $\mathrm{Fv} / \mathrm{Fm}$, an indicator that characterizes the efficiency of energy trapping in the PSII RCs, was different between the cultivars which had various freezing-tolerance capacities during the recovery stage [21]. The cold-tolerant ecotypes (Miscanthus and Saccharum) were able to cope with applied low temperature stress by down-regulating PSII RCs, whereas the cold-sensitive ecotypes had a generally lower capacity for dynamic photoinhibition and sustain photodamage [37]. The strong cold-tolerance of sorghum PSII to photo-inactivation was because of its more effective dissipation capacity of the excess of energy and to a more balanced diversion of the absorbed energy into alternative energy sinks [38]. In winter, the cold resistant tea cultivar always contains higher level of soluble carbohydrates than the cold sensitive cultivar, resulting in lower freezing point temperature in the former than that in the later [35]. During cold stress, cold-tolerant accessions of Arabidopsis thaliana maintain higher PSII activity and higher capacity for sucrose synthesis than the cold sensitive accessions [39]. That is why cold resistant inbred lines of crops could be screened by analyzing the ChlF under cold stress $[19,20,22]$.

The proteins D1 and D2 in chloroplast are two key subunits in the PSII RCs and they are present in association with chlorophyll and pheophytin [40]. The D1/D2 heterodimer may serve a similar function in PSII in a plant to that of the L/M pair in the bacterial reaction center [41]. The D1 protein is a key target of environmental stress [29]. The present study shows that the expression of gene $p s b A$ encoding D1 protein in freezing sensitive tea cultivars ' $5-62$ ' was greatly downregulated whereas that in highly freezing-tolerant tea cultivars ' $4-52$ ' and ' $4-77$ ' was significantly upregulated after freezing treatment, with moderate freezing-sensitive cultivars ' $5-7$ ' and 'Fuding' in between showing less change (Figure 1). This is consistent with the findings in Zea mays and Colobanthus quitensis that the cold tolerant genotypes were able to maintain D1 protein level after photoinhibitory conditions by upregulating $p s b A$ mRNA levels for the D1 biosynthesis [42,43]. The involvement of D2 subunit in the responses to low temperatures may vary with plant species. A study on lotus species showed that the D2 subunit was more severely affected by low temperature exposure than D1 [44]. However, this study 
showed no obvious relationship between the $p s b D$ expression and freezing tolerance of tea cultivars (Figure 2). These results suggest that the freezing-induced decrease in Fv/Fm of the freezing sensitive tea cultivar might be a consequence of its weak dynamic capacity to balance the synthesis and loss of D1 protein. Analysis of the expression of gene $p s b A$ encoding the D1 is considered to be used as a selection tool for freezing tolerance of photosynthesis in tea breeding.

Furthermore, the agronomic measures that could promote the expression of $p s b A$ will be beneficial to enhance the freezing tolerance of crops. There was a study showing that the gene WHY1 binding to the upstream region of $p s b A$ enhanced the cold tolerance of tomato by increasing the de novo synthesis of D1 protein and maintaining the function of PSII in chloroplasts [45]. The application of chitooligosaccharides could enhance cold tolerance of rice by repairing the photodamaged PSII through upregulating $p s b A$ [46]. This technique is worth trying in the high latitude tea growing areas with severely freezing winter.

Tea leaf contains both TP and polyphenol oxidase (PPO). In the intact leaf, the TP which is suspended in the vacuoles is separated from the PPO that is bound to the thylakoid membrane. However, they will contact each other when the protoplasmic membrane systems were damaged by environmental stress, in which the PPO will catalyze the TP oxidation, resulting in the changes in leaf color from green to red brown. In selection of black tea cultivars, fresh tea leaves of various tested hybrid plants or clonal cultivars were placed in a sealed container with chloroform for e few hours, during which the protoplasmic membrane system of the leaves was injured by the chloroform vapour and the TP was oxidized, and then the fermenting abilities of the tested tea cultivars were assessed according to the redness of the leaves [24]. In the present study, the leaves on tea shoots were frozen at $-15^{\circ} \mathrm{C}$ for $2 \mathrm{~h}$ and then stood at room temperature for $5 \mathrm{~h}$, during which the protoplasmic membrane systems in leaves on the freezing sensitive cultivars with high freezing point temperature were injured more seriously than the freezing tolerant cultivars, resulting in differentiation in TP oxidation and changes in the "green-red" indicator $a$ on the Hunter color scale. That is why the " $a$ " ratio of the frozen group to the control group $\left(\mathrm{R}_{a}\right)$ showed significantly regressive relationship to the freezing sensitivity index $\mathrm{H}\left(\mathrm{H}=30.03-10.82 \mathrm{R}_{a}, p<0.01\right)$. This will provide a tool for instrumental screening freezing tolerant tea plants from a population of hybrid plant individuals.

\section{Materials and Methods}

\subsection{Plant Materials}

Plant materials used in the present paper were forty seven tea clonal cultivars with 8-year-old, grown in Tea Farm of Zhejiang University, Hangzhou, China $\left(120.30^{\circ} \mathrm{E}, 30.42^{\circ} \mathrm{N}\right)$. The tea plants were planted in random block design, in which 15 plants in each block, with three replicates. On 24 January 2016, the lowest temperature was $-10^{\circ} \mathrm{C}$ (Figure S1), which was the lowest temperature since 2011. The plants of various tea cultivars showed obvious differences in the freezing-induced injuries with the temperature increase. The freezing-induced injuries of these cultivars were differentiated in the middle of February 2016 when the temperature increased to $20^{\circ} \mathrm{C}$ or above (Figure S2). The field survey was carried out on 15 February 2016.

\subsection{Investigation of Freezing-Induced Injuries}

The plants (5 plants each block) for freezing-induced injuries investigation were randomly chosen, and then the healthy leaves and the freezing-induced injured leaves on the plants were counted separately. The freezing sensitivity index $(\mathrm{H})$ was calculated by the following equation [47]: $\mathrm{H}(\%)=$ $\left[\Sigma\left(\mathrm{n}_{i} \times \mathrm{x}_{i}\right) /(\mathrm{N} \times 4)\right] \times 100$.

Where the $\mathrm{H}$ is freezing sensitivity index, $\mathrm{n}_{i}$ is the number plant with a freezing-sensitive score $i$ in the five grading system (Table S2), $\mathrm{x}_{i}$ is the freezing-sensitive score $i$ in the five grading systems, $\mathrm{N}$ is the total plant number of the investigated cultivar, 4 is the highest score of $i$ in the five grading system (Table S2). The freezing tolerance of a cultivar was evaluated based on the H value (Table S3): highly 
freezing-tolerant $(\mathrm{H}<10.0)$, freezing-tolerant $(10.0 \leq \mathrm{H}<20.0)$, moderate freezing-sensitive $(20.0 \leq \mathrm{H}$ $<50.0)$ and freezing-sensitive $(H \geq 50.0)$ [47].

\subsection{Freezing Treatment}

\subsubsection{Effect of Freezing Temperature on Changes in Leaf Color}

The green color of fresh tea leaves will change into brown color when the protoplasmic membrane system in the leaf cells is damaged by stress conditions such as chloroform vapor, heating and freezing due to the oxidation of foliar TP [24]. To find an optimum temperature to treat the tea shoots for assessing the freezing tolerance of various tea cultivars, 25 tea shoots with an apex bud and six leaves were cut from each tea cultivar (cultivars ' $\mathrm{FZ}-0$ ' , ' $1-17^{\prime}$, ' $4-63$ ', and ' $1-10$ ') and then randomly divided into five groups ( 5 shoots each). One group ( 5 shoots) was placed in a $500-\mathrm{mL}$ beaker with $200 \mathrm{~mL}$ purified water at $20{ }^{\circ} \mathrm{C}$ (control group). The other four groups (five shoots each) were placed in refrigerators setting at $-5,-10,-15$, and $-20^{\circ} \mathrm{C}$ for $2 \mathrm{~h}$, respectively, and then were took out and placed in $500-\mathrm{mL}$ beakers containing $200 \mathrm{~mL}$ purified water at $20^{\circ} \mathrm{C}$ as the control group, during which the changes in leaf color were observed every hour. The observation showed that little change in leaf color for treatments at -5 and $-10^{\circ} \mathrm{C}$. The color of the frozen leaves treated at -15 and $-20^{\circ} \mathrm{C}$ changed obviously from second hour after placing in the $500-\mathrm{mL}$ beaker containing water and the colors were stabilized after $5 \mathrm{~h}$ (Figure S3). Therefore, in the subsequent freezing treatment, the tea shoots were frozen at $-15{ }^{\circ} \mathrm{C}$ for $2 \mathrm{~h}$ and then stood in $500-\mathrm{mL}$ beaker containing $200 \mathrm{~mL}$ purified water for $5 \mathrm{~h}$ before $\mathrm{Fv} / \mathrm{Fm}$ testing and colorimetric testing.

\subsubsection{Freezing Treatment of Various Tea Cultivars}

Based on the above results, the control group (5 shoots each cultivar) was treated as before, and the tested group ( 5 shoots each cultivar) of shoots with an apex bud and six leaves were frozen at $-15^{\circ} \mathrm{C}$ for $2 \mathrm{~h}$ and then stood in 500-mL beaker containing $200 \mathrm{~mL}$ purified water for $5 \mathrm{~h}$ at room temperature before $\mathrm{Fv} / \mathrm{Fm}$ testing and colorimetric testing, in which the fourth leaves beneath apex bud of the frozen and control groups were picked for testing.

\subsection{Fv/Fm Testing}

The maximum photochemical efficiency of PSII (Fv/Fm, the ratio of variable (Fv) to maximum $(\mathrm{Fm})$ fluorescence $\left(\mathrm{Fv} / \mathrm{Fm}=\left(\mathrm{Fm}-\mathrm{F}_{0}\right) / \mathrm{Fm}\right)$ in the frozen and control groups of each cultivar was determined using a Handy PEA fluorimeter (Plant Efficient Analyzer, Hansatech Instruments Ltd., King's Lynn, Norfolk, UK). The leaves were dark-adapted for $20 \mathrm{~min}$ before measurement. The values of Fv/Fm were read on the Handy PEA fluorimeter [25], which were used to assess the PSII activity. Five leaves were tested for each treatment.

\subsection{Test of Expression of Genes $p s b A$ and $p s b D$}

The expression of gene $p s b A$ encoding D1 protein and gene $p s b D$ encoding D2 protein was tested by real-time quantitative PCR (rt-qPCR). The extraction of total RNA and synthesis of cDNA were carried out by a previous method [48]. The rt-qPCR primers of $p s b A$ (genome ID: TEA001596.1) and $p s b D$ (genome ID: TEA011225.1) (Table S4) were designed according to the published reference genome [49]. The rt-qPCRs were conducted on a StepOne Plus Real-Time PCR system (Applied Biosystems, Foster City, CA, USA) using PowerUp ${ }^{\mathrm{TM}}$ SYBR ${ }^{\mathrm{TM}}$ Green Master Mix (Applied Biosystems, Foster City, CA, USA) for the detection of PCR products. Each reaction was performed in a final volume of $15 \mu \mathrm{L}$, including $5.4 \mu \mathrm{L}$ sterile deionized water, $7.5 \mu \mathrm{L}$ SYBR Mix, $0.45 \mu \mathrm{L}$ primer $(600 \mathrm{nM})$ and $1.2 \mu \mathrm{L}$ cDNA template $(60 \mathrm{ng})$. The thermal cycling conditions were $95^{\circ} \mathrm{C}$ for $2 \mathrm{~min}$, followed by 40 cycles of $95^{\circ} \mathrm{C}$ for $3 \mathrm{~s}, 60^{\circ} \mathrm{C}$ for $30 \mathrm{~s}$ with fluorescence detection at the end of each cycle and confirmation by melting curve analysis. The rt-qPCR test was generated using triplicate leaf samples and each sample was tested in technical triplicates. Each relative expression level was calculated using the $2^{-\Delta \Delta C T}$ method 
with $\beta$-actin gene as internal control [50]. The relative expression values were firstly normalized using $\beta$-actin gene as an internal reference. For plant materials for rt-qPCR, totally six clonal tea cultivars were chosen from the groups of highly freezing-tolerant, moderate freezing-sensitive and freezing-sensitive cultivars, respectively.

\subsection{Colorimetric Testing}

Indicators of $L, a$ and $b$ on the Hunter color scales for the leaves of the frozen group and control group were determined using an UltraScan VIS1195 HunterLab colorimeter (Hunter Associates Laboratory, Inc., Reston, VA, USA) according to the guidelines of the instrument.

\subsection{Statistic Analysis}

The biological repeat was 3 (blocks) and technical repeat was 5 ( 5 plants each block) in this study. Analysis of weighted means, standard deviation, Pearson's linear correlation coefficients, and linear regression was carried out on software IBM SPSS Statistics V20.

\section{Conclusions}

The freezing tolerances of tea cultivars are differentiated as normal rule distribution, in which a few are highly freezing-tolerant and freezing sensitive respectively, with most of them being moderate freezing-sensitive. Traditionally, freezing-tolerant tea plants were screened from a big population of hybrid tea plants after severely freezing weather, and this operation took a few years but the selection effectiveness was dependent on the weather conditions. Developing a feasible instrumental method for screening freezing-tolerant plant individuals from the tested breeding population will be significant for breeding highly freezing-tolerant tea cultivars. When tea shoots with six leaves and a bud were frozen at $-15{ }^{\circ} \mathrm{C}$ for $2 \mathrm{~h}$ and then stood at room temperature $\left(20^{\circ} \mathrm{C}\right)$ for $5 \mathrm{~h}$, the maximum photochemical efficiency of PSII (Fv/Fm), the expression of gene $p s b A$ encoding D1 protein in PSII CRs and leaf color indicator $a$ on the Hunter color scale were obviously differentiated between tea cultivars with various freezing tolerances, among which the Fv/Fm ratio of the frozen group to control group $\left(\mathrm{R}_{\mathrm{Fv} / \mathrm{Fm}}\right)$ and the $a$ ratio of frozen group to control group $\left(\mathrm{R}_{a}\right)$ showed significantly linear regressive relationship to the freezing sensitivity index $(\mathrm{H})$ obtained by field surveys after severe freezing weather, with $\mathrm{H}=$ $60.31-50.09 \mathrm{R}_{\mathrm{Fv} / \mathrm{Fm}}(p<0.01)$ and $\mathrm{H}=30.03-10.82 \mathrm{R}_{a}(p<0.01)$. These will provide instrumental tools for the assistant selection of freezing tolerant cultivars in the tea breeding program.

Supplementary Materials: The following are available online at http://www.mdpi.com/2223-7747/8/10/434/s1, Figure S1: Monthly changes in maximum (upper) and minimum (lower) temperature during 2011-2018 in Hangzhou; Figure S2: Daily changes in maximum (blue line) and minimum (yellow line) temperature during February 2016 in Hangzhou; Figure S3: Effect of freezing on leaf color of various tea cultivars, Table S1: The linear correlation and regressive relationship between various tested indicators; Table S2: Freezing-sensitive score based on freezing-induced injured leaves on a plant; Table S3: Freezing tolerance classification of tea cultivars based on H index; Table S4: The rt-qPCR primers used in the test.

Author Contributions: Conceived and designed the project, Y.-R.L. and X.-Q.Z.; performed the experiments and analyzed the data, Y.-L.S., Z.-Y.C., D.L., and J.-L.L.; wrote the manuscript, Y.-R.L., X.-Q.Z., and J.-H.Y. All authors reviewed and approved the manuscript.

Funding: This research was funded by grants from the National Natural Science Foundation of China (No. 31170643), China Agriculture Research System (Tea) (No. CARS-19) and the Science Technology Department of Zhejiang Province (No. 2752016C02053-5).

Acknowledgments: The authors appreciate the National Natural Science Foundation of China, China Agriculture Research System (Tea) and the Science Technology Department of Zhejiang Province for financial supporting this study.

Conflicts of Interest: The authors declare no competing interest. 


\section{References}

1. Yang, Y.J.; Liang, Y.R. Clonal Tea Cultivars in China; Shanghai Century Publishing Co., Ltd.: Shanghai, China, 2014. (In Chinese)

2. Wang, Y.; Hong, Y.; Ding, Z.; Zhang, X.; Wang, Y.; Fan, K. Cold resistant prediction of tea germplasm resources applied by anatomical structure index of leaves. Chin. Agric. Sci. Bull. 2009, 25, 126-130. (In Chinese)

3. Hou, Y.; Tang, M.; Hu, X. Evaluations of cold resistance of tea germplasm resources. Southwest China J. Agric. Sci. 2010, 23, 137-140. (In Chinese) [CrossRef]

4. Wang, Y.; Jiang, C.J.; Li, Y.Y.; Wei, C.L.; Deng, W.W. CsICE1 and CsCBF1: Two transcription factors involved in cold responses in Camellia sinensis. Plant Cell Rep. 2012, 31, 27-34. [CrossRef] [PubMed]

5. Wang, Y.-X.; Liu, Z.-W.; Wu, Z.-J.; Li, H.; Zhuang, J. Transcriptome-Wide Identification and Expression Analysis of the NAC Gene Family in Tea Plant [Camellia sinensis (L.) O. Kuntze]. PLoS ONE 2016, 11, e0166727. [CrossRef]

6. Ban, Q.; Wang, X.; Pan, C.; Wang, Y.; Kong, L.; Jiang, H.; Xu, Y.; Wang, W.; Pan, Y.; Li, Y.; et al. Comparative analysis of the response and gene regulation in cold resistant and susceptible tea plants. PLOS ONE 2017, 12, e0188514. [CrossRef]

7. Li, N.-N.; Yue, C.; Cao, H.-L.; Qian, W.-J.; Hao, X.-Y.; Wang, Y.-C.; Wang, L.; Ding, C.-Q.; Wang, X.-C.; Yang, Y.-J. Transcriptome sequencing dissection of the mechanisms underlying differential cold sensitivity in young and mature leaves of the tea plant (Camellia sinensis). J. Plant Physiol. 2018, 224, 144-155. [CrossRef]

8. Wang, L.; Yao, L.; Hao, X.; Li, N.; Wang, Y.; Ding, C.; Lei, L.; Qian, W.; Zeng, J.; Yang, Y.; et al. Transcriptional and physiological analyses reveal the association of ROS metabolism with cold tolerance in tea plant. Environ. Exp. Bot. 2019, 160, 45-58. [CrossRef]

9. Eggert, A.; Van Hasselt, P.R.; Breeman, A.M. Differences in thermal acclimation of chloroplast functioning in two ecotypes of Valonia utricularis (Chlorophyta). Eur. J. Phycol. 2003, 38, 123-131. [CrossRef]

10. Skupień, J.; Wójtowicz, J.; Kowalewska, Ł; Mazur, R.; Garstka, M.; Gieczewska, K.; Mostowska, A. Dark-chilling induces substantial structural changes and modifies galactolipid and carotenoid composition during chloroplast biogenesis in cucumber (Cucumis sativus L.) cotyledons. Plant Physiol. Biochem. 2017, 111, 107-118.

11. Ma, X.; Chen, C.; Yang, M.; Dong, X.; Lv, W.; Meng, Q. Cold-regulated protein (SlCOR413IM1) confers chilling stress tolerance in tomato plants. Plant Physiol. Biochem. 2018, 124, 29-39. [CrossRef]

12. Levy, M.; Bachmair, A.; Adam, Z. A single recessive mutation in the proteolytic machinery of Arabidopsis chloroplasts impairs photoprotection and photosynthesis upon cold stress. Planta 2004, 218, 396-405. [CrossRef] [PubMed]

13. Eggert, A.; Van Hasselt, P.R.; Breeman, A.M. Chilling-induced photoinhibition in nine isolates ofValonia utricularis (Chlorophyta) from different climate regions. J. Plant Physiol. 2003, 160, 881-891. [CrossRef] [PubMed]

14. Wang, Y.; Jiang, Q.; Liu, J.; Zeng, W.; Zeng, Y.; Li, R.; Luo, J. Comparative transcriptome profiling of chilling tolerant rice chromosome segment substitution line in response to early chilling Stress. Genes Genom. 2017, 39, 127-141. [CrossRef]

15. Garstka, M.; Venema, J.H.; Rumak, I.; Gieczewska, K.; Rosiak, M.; Koziol-Lipinska, J.; Kierdaszuk, B.; Vredenberg, W.J.; Mostowska, A. Contrasting effect of dark-chilling on chloroplast structure and arrangement of chlorophyll-protein complexes in pea and tomato: Plants with a different susceptibility to non-freezing temperature. Planta 2007, 226, 1165-1181. [CrossRef]

16. Roach, T.; Krieger-Liszkay, A.K. Regulation of Photosynthetic Electron Transport and Photoinhibition. Curr. Protein Pept. Sci. 2014, 15, 351-362. [CrossRef]

17. Sasi, S.; Venkatesh, J.; Daneshi, R.F.; Gururani, M.A. Photosystem II Extrinsic Proteins and Their Putative Role in Abiotic Stress Tolerance in Higher Plants. Plants 2018, 7, 100. [CrossRef]

18. Wise, R.R. Chilling-enhanced photooxidation: The production, action and study of reactive oxygen species produced during chilling in the light. Photosynth. Res. 1995, 45, 79-97. [CrossRef]

19. Fracheboud, Y. Chlorophyll fluorescence as a selection tool for cold tolerance of photosynthesis in maize (Zea mays L.). J. Exp. Bot. 1999, 50, 1533-1540. [CrossRef] 
20. Kościelniak, J.; Janowiak, F.; Kurczych, Z. Increase in photosynthesis of maize hybrids (Zea mays L.) at suboptimal temperature $\left(15^{\circ} \mathrm{C}\right)$ by selection of parental lines on the basis of chlorophyll a fluorescence measurements. Photosynthetica 2005, 43, 125-134. [CrossRef]

21. Rapacz, M. Chlorophyll a fluorescence transient during freezing and recovery in winter wheat. Photosynthetica 2007, 45, 409-418. [CrossRef]

22. Mishra, A.; Heyer, A.G.; Mishra, K.B. Chlorophyll fluorescence emission can screen cold tolerance of cold acclimated Arabidopsis thaliana accessions. Plant Methods 2014, 10, 38. [CrossRef] [PubMed]

23. Zhou, R.; Wu, Z.; Wang, X.; Rosenqvist, E.; Wang, Y.; Zhao, T.; Ottosen, C.-O. Evaluation of temperature stress tolerance in cultivated and wild tomatoes using photosynthesis and chlorophyll fluorescence. Hortic. Environ. Biotechnol. 2018, 59, 499-509. [CrossRef]

24. Toyao, T. Varietal difference and breeding-behavior of fermentation ability (polyphenol oxidase activity) in tea plants. Jpn. Agric. Res. Q. 1984, 18, 37-42.

25. Krause, G.H.; Weis, E. Chlorophyll Fluorescence and Photosynthesis: The Basics. Annu. Rev. Plant Boil. 1991, 42, 313-349. [CrossRef]

26. Cai, W.; Ma, J.; Guo, J.; Zhang, L. Function of ROC4 in the Efficient Repair of Photodamaged Photosystem II inArabidopsis. Photochem. Photobiol. 2008, 84, 1343-1348. [CrossRef]

27. Nixon, P.J.; Rögner, M.; Diner, B.A. Expression of a higher plant psbA gene in Synechocystis 6803 yields a functional hybrid photosystem II reaction center complex. Plant Cell 1991, 3, 383-395.

28. Yuan, M.; Zhang, H.-Y.; Yuan, S.; Chen, Y.-E.; Liu, W.-J.; Su, Y.-Q.; Cui, J.-M.; Zhang, Z.-W.; Chen, Y.; Liu, W.; et al. Different response of photosystem II to short and long-term drought stress in Arabidopsis thaliana. Physiol. Plant. 2016, 158, 225-235.

29. Yamamoto, Y.; Aminaka, R.; Yoshioka, M.; Khatoon, M.; Komayama, K.; Takenaka, D.; Yamashita, A.; Nijo, N.; Inagawa, K.; Morita, N.; et al. Quality control of photosystem II: Impact of light and heat stresses. Photosynth. Res. 2008, 98, 589-608. [CrossRef]

30. Zhao, H.-J.; Zhao, X.-J.; Ma, P.-F.; Wang, Y.-X.; Hu, W.-W.; Li, L.-H.; Zhao, Y.-D. Effects of salicylic acid on protein kinase activity and chloroplast D1 protein degradation in wheat leaves subjected to heat and high light stress. Acta Ecol. Sin. 2011, 31, 259-263. [CrossRef]

31. Kiss, E.; Kós, P.B.; Chen, M.; Vass, I. A unique regulation of the expression of the psbA, psbD, and psbE genes, encoding the D1, D2 and cytochrome b559 subunits of the Photosystem II complex in the chlorophyll d containing cyanobacterium Acaryochloris marina. Biochim. Biophys. Acta (BBA) Gen. Subj. 2012, 1817, 1083-1094. [CrossRef]

32. Wang, Y.; Wei, S.; Wang, J.; Su, X.; Suo, B.; Qin, F.; Zhao, H. Exogenous application of 5-aminolevulinic acid on wheat seedlings under drought stress enhances the transcription of psbA and psbD genes and improves photosynthesis. Braz. J. Bot. 2018, 41, 275-285. [CrossRef]

33. Liang, Y.; Wu, Y.; Lu, J.; Zhang, L. Application of chemical composition and infusion colour difference analysis to quality estimation of jasmine-scented tea. Int. J. Food Sci. Technol. 2007, 42, 459-468. [CrossRef]

34. Okano, K.; Matsuo, K. Winter-depression of Photosynthesis in Tea Plants with Special Reference to Cultivar and Leaf Age. Jpn. J. Crop. Sci. 1994, 63, 240-246. [CrossRef]

35. Takeda, Y. History and development in Japanese tea breeding. In Tea Culture, Tea Food Industry and Tea Tree Breeding in Korea, China and Japan; Park, Y.G., Shin, D.I., Eds.; International Symposium on Tea Culture, Tea Food Industry and Tea Tree Breeding: Taegu, Korea, 2000; pp. 139-158.

36. Fu, J.; Gates, R.N.; Xu, Y.; Hu, T. Diffusion limitations and metabolic factors associated with inhibition and recovery of photosynthesis following cold stress in Elymus nutans Griseb. J. Photochem. Photobiol. B Boil. 2016, 163, 30-39. [CrossRef] [PubMed]

37. Friesen, P.C.; Peixoto, M.M.; Busch, F.A.; Johnson, D.C.; Sage, R.F. Chilling and frost tolerance in Miscanthus and Saccharum genotypes bred for cool temperate climates. J. Exp. Bot. 2014, 65, 3749-3758. [CrossRef]

38. Zegada-Lizarazu, W.; Monti, A. Differential characteristics of photochemical acclimation to cold in two contrasting sweet sorghum hybrids. Physiol. Plant. 2016, 157, 479-489. [CrossRef]

39. Nägele, T.; Stutz, S.; Hörmiller, I.I.; Heyer, A.G. Identification of a metabolic bottleneck for cold acclimation inArabidopsis thaliana. Plant J. 2012, 72, 102-114. [CrossRef]

40. Nanba, O.; Satoh, K. Isolation of a photosystem II reaction center consisting of D-1 and D-2 polypeptides and cytochrome b-559. Proc. Natl. Acad. Sci. USA 1987, 84, 109-112. [CrossRef] 
41. Marder, J.B.; Chapman, D.J.; Telfer, A.; Nixon, P.J.; Barber, J. Identification of psbA and psbD gene products, D1 and D2, as reaction centre proteins of photosystem 2. Plant Mol. Boil. 1987, 9, 325-333. [CrossRef]

42. Bascuñán-Godoy, L.; Sanhueza, C.; Cuba, M.; Zuñiga, G.E.; Corcuera, L.J.; Bravo, L.A. Cold-acclimation limits low temperature induced photoinhibition by promoting a higher photochemical quantum yield and a more effective PSII restoration in darkness in the Antarctic rather than the Andean ecotype of Colobanthus quitensis Kunt Bartl (Cariophyllaceae). BMC Plant Boil. 2012, 12, 114.

43. Spence, A.K.; Boddu, J.; Wang, D.; James, B.; Swaminathan, K.; Moose, S.P.; Long, S.P. Transcriptional responses indicate maintenance of photosynthetic proteins as key to the exceptional chilling tolerance of $\mathrm{C} 4$ photosynthesis in Miscanthus $\times$ giganteus. J. Exp. Bot. 2014, 65, 3737-3747. [CrossRef] [PubMed]

44. Calzadilla, P.I.; Signorelli, S.; Escaray, F.J.; Menéndez, A.B.; Monza, J.; Ruiz, O.A.; Maiale, S.J. Photosynthetic responses mediate the adaptation of two Lotus japonicus ecotypes to low temperature. Plant Sci. 2016, 250, 59-68. [CrossRef] [PubMed]

45. Zhuang, K.Y.; Kong, F.Y.; Zhang, S.; Meng, C.; Yang, M.M.; Liu, Z.B.; Wang, Y.; Ma, N.N.; Meng, Q.W. Whirly1 enhances tolerance to chilling stress in tomato via protection of photosystem II and regulation of starch degradation. New Phytol. 2019, 221, 1998-2012. [CrossRef] [PubMed]

46. Zhou, J.; Chen, Q.; Zhang, Y.; Fan, L.; Qin, Z.; Chen, Q.; Qiu, Y.; Jiang, L.; Zhao, L. Chitooligosaccharides enhance cold tolerance by repairing photodamaged PS II in rice. J. Agric. Sci. 2018, 156, 888-899. [CrossRef]

47. Huang, H.T.; Zhang, W.; Mao, X.Y.; Yu, J.Z. Identification and evaluation of winter hardiness of tea varieties in Zhejiang Province. J. Zhejiang Agric. Sci. 2017, 58, 1328-1329. (In Chinese) [CrossRef]

48. Shi, Y.-L.; Sheng, Y.-Y.; Cai, Z.-Y.; Yang, R.; Li, Q.-S.; Li, X.-M.; Li, D.; Guo, X.-Y.; Lu, J.-L.; Ye, J.-H.; et al. Involvement of Salicylic Acid in Anthracnose Infection in Tea Plants Revealed by Transcriptome Profiling. Int. J. Mol. Sci. 2019, 20, 2439. [CrossRef]

49. Wei, C.; Yang, H.; Wang, S.; Zhao, J.; Liu, C.; Gao, L.; Xia, E.; Lu, Y.; Tai, Y.; She, G.; et al. Draft genome sequence of Camellia sinensis var. sinensis provides insights into the evolution of the tea genome and tea quality. Proc. Natl. Acad. Sci. USA 2018, 115, E4151-E4158. [CrossRef]

50. Livak, K.J.; Schmittgen, T.D. Analysis of relative gene expression data using real-time quantitative PCR and the 2(T)(-Delta Delta C) method. Methods 2001, 25, 402-408. [CrossRef] 